\title{
The Effect of Attachment Styles on Positive Communication and Sexual Satisfaction in Relationships
}

\author{
Ashley Barnes, Mary Dodson, Benjamin Wood, Heather Thomas, and Claire Kimberly \\ University of Southern Mississippi
}

Sexual satisfaction is strongly related to a couple's perception of their overall relationship satisfaction and personal wellbeing (Brassard, Dupuy, Bergeron, \& Shaver, 2015; Butzer \& Campbell, 2008). Sexual satisfaction can be enhanced by positive communication between partners (Brassard et al., 2015; Davis et al., 2006), but how individuals obtain this skill is difficult to decipher. This study therefore examines the relationship between an individual's attachment style and its relationship to couples' sexual satisfaction, sexual communication anxiety, and sexual attitudes. Attachment theory proposes that early childhood intimate encounters are the foundations that will shape an individual's attachment later in life (Ainsworth, et al., 1978; Bowlby, 1982). Therefore, these encounters can help clarify the comfort and ability of couples to positively communicate with one another about their sexual desires and needs.

\section{Brief Literature Review}

According to attachment theory (Ainsworth et al., 1978; Bowlby, 1982), the relationships formed in childhood influence feelings and behaviors in later adult romantic relationships. A secure child develops a sense of self-worth, positive expectations, and effective emotional regulation when caregivers provide sensitive and consistent care (Bowlby, 1982; Brassard et al., 2015). An anxious-insecure attachment style is characterized by an increase in anxiety and negative emotional expression, while the avoidant attachment style favors emotional suppression, and a lack of self-disclosure to a partner (Brassard et al., 2015). Thus, those with insecure attachment styles are more likely to engage in casual sex and promiscuity, and often experience low levels of commitment and intimacy (Dempster, et al., 2015).

Previous research has supported the relationship between attachment styles and later physical and emotional romantic satisfaction. Butzer and Campbell (2008) studied 116 married couples from Canada and found that higher levels of anxiety and avoidance correlated with lower levels of sexual satisfaction. Avoidantly attached individuals reported lower levels of sexual satisfaction in their marriage even after controlling for both partners' levels of attachment anxiety. This suggests that avoidant individuals' discomfort with intimacy extends to the sexual relationship with their spouse. Davis and colleagues (2006) surveyed 1,989 people and found that sexual communication inhibition and avoidance are positively related. Individuals with an insecure-anxious attachment have difficulties expressing themselves in a sexually assertive manner, suggesting that the more secure the attachment is to one's intimate partner, the more likely the couple will participate in sexually assertive conversations and have higher levels of sexual satisfaction. No known research, though, has taken a look at how attachment styles might relate to positive sexual communication skills, attitudes, and subsequently, sexual satisfaction. 


\section{Method}

\section{Participants}

Four hundred and twenty-five subjects voluntarily participated in this research study. Ages ranged from 20 to 76 years old $(M=27.81 ; s d=8.08)$. Females $(n=372 ; 84.8 \%)$ substantially outnumbered males $(n=53 ; 11.3 \%$; no participants selected the "other" option provided for gender identity) in the sample. A majority of the participants were AfricanAmerican $(n=237 ; 54.7 \%)$ followed by Caucasian $(n=151 ; 34.9 \%)$, with the final ethnicities (10.4\%) being evenly dispersed among Hispanic, Asian, Native American, and other. The most frequent attachment style was found to be the secure attachment style at 132 (31.7\%) participants, followed by anxious-avoidant $(n=94 ; 22.5 \%)$, avoidant $(n=58$; $13.9 \%)$, and preoccupied $(n=40 ; 9.6 \%)$.

\section{Measures}

Attitudes about sexuality. The Brief Sexual Attitudes Scale (BSAS; Hendrick, Hendrick, \& Reich, 2006) was developed as a shorter version of the Sexual Attitudes Scale (Hendrick \& Hendrick, 1987). Participants respond to the 23 -item measurement by rating each item on a five-point Likert scale ranging from strongly agree to strongly disagree. The BSAS consists of four subscales: permissiveness (casual sex), birth control (responsible sexual practices), communion (relational), and instrumentality (biological aspects and enjoyment). The BSAS has previously shown high alpha values of .70 and greater with testretest correlations greater than .75 (Hendrick et al., 2006; Kimberly, Werner-Wilson, \& Motes, 2013). The sub-scales for the present study resulted in Cronbach alphas of 0.94 for permissiveness $(M=24.59, s d=8.38), 0.87$ for birth control $(M=12.53, s d=2.48), 0.81$ for communion $(M=18.70, s d=3.63)$, and 0.84 for instrumentality $(M=14.53$, $s d=4.26)$.

Sexual communication. The Inhibition of Need Expression Scale (Davis, Shaver, Widaman, Vernon, Follette, \& Beitz, 2006) consists of 9 items that assess anxiety about communicating sexual topics. Participants were prompted to respond using a 9-point Likert scale ranging from not at all true of me to extremely true of me. Sample questions include "It is easy for me to tell my partner what I need him/her to do to satisfy me sexually" and "Even when I'm really in the mood to have sex, I prefer to wait to let my partner initiate sex". The Cronbach alpha for this study was .71 with a $M$ of 69.57 and $s d$ of 20.33 .

Sexual satisfaction. Sexual satisfaction was assessed using the Physical Satisfaction Scale (Davis et al., 2006). Ten items were used to measure participants' satisfaction with such items as "Satisfied with the sexual skills of your partner" and "Satisfied with the sexual attractiveness of your partner." Response options range from $1=$ not at all to $5=$ very much. The $M$ for this study was 39.3 with a sd of 8.9 ; Cronbach alpha was .85 .

Attachment Styles. As used in other empirical articles (e.g., Kidd, Hamer, \& Steptoe, 2011), Batholomew and Horowitz' (1991) definition of secure, preoccupied, avoidant, and anxious-avoidant attachment styles were used to assess participants' 
attachment styles. Participants were asked to select the style that best described themselves. The description of secure attachment was as follows:

It is easy for me to become emotionally close to others. I am comfortable depending on them and having them depend on me. I don't worry about being alone or having others not accept me.

\section{Procedure}

An Internet survey was created using Qualtrics survey. Participants were recruited from undergraduate and graduate college classes on a southeastern college campus, as well as through outreach on a social media event page. No identifying information was collected in order to protect the subject's confidentiality. The procedures were approved by the authors' Institutional Review Board.

\section{Results}

Correlations between variables were tested using Spearman's correlation coefficients (see Table 1). Results indicated that there was a significant, positive correlation between secure attachment style and openness about birth control, sexual communication, and physical satisfaction scale total. Negative relationships were found between physical satisfaction and the preoccupied, anxious-avoidant, and avoidant attachment styles. The preoccupied attachment style was negatively related to instrumental and permissiveness attitudes, while positively related to birth control and communion attitudes. Anxiousavoidant attachment style was negatively related to all of the sexual attitudes with the notable exception of permissiveness. Avoidant attachment style revealed more diversity with a negative relationship between birth control and communion attitudes, but a positive relationship with instrumental and permissive attitudes. Finally, anxiety surrounding communicating about sexual topics was positively related to the anxious-avoidant and avoidant attachment styles, but negatively related to the preoccupied attachment style.

Table 1. Means, Standard Deviations, and Intercorrelations for Independent and Dependent Variables.

\begin{tabular}{|c|c|c|c|c|c|c|c|c|}
\hline Variable & Mean & $s d$ & $\begin{array}{c}\text { Birth } \\
\text { Control }\end{array}$ & Communion & Instrumental & Permissiveness & $\begin{array}{l}\text { INE } \\
\text { Total }\end{array}$ & $\begin{array}{l}\text { PSS } \\
\text { Total }\end{array}$ \\
\hline Secure & .32 & .47 & $.102 *$ & $.149 * *$ & .090 & .069 & -.005 & $.141 * *$ \\
\hline Preoccupied & .10 & .30 & .062 & .080 & -.044 & -.059 & -.023 & -.061 \\
\hline $\begin{array}{l}\text { Anxious- } \\
\text { Avoidant }\end{array}$ & .23 & .42 & -.010 & -.074 & -.037 & .038 & .006 & -.059 \\
\hline Anxious & .14 & .35 & -.028 & -.085 & .066 & .090 & .048 & -.022 \\
\hline
\end{tabular}

** Correlation is significant at the 0.01 level (2-tailed). 
A one-way between-groups analysis of variance was conducted to explore the impact of attachment styles on physical satisfaction, sexual attitudes, and sexual communication. There was a statistically significant difference at the $p<.05$ level in secure attachment styles with physical satisfaction $[F(1,424)=7.01, p=.008]$ and the subscale scores of birth control $[F(1,424)=4.15, p=.04]$ and communion $[F(1,424)=8.96, p=.003]$. Despite reaching statistical significance, the actual difference in mean scores between the groups was quite small (effect sizes--measured by eta-square--resulting in .02, .01, .02 respectively). No other significant findings resulted from this test.

\section{Discussion}

The most significant associations found in this study were positive correlations and statistical differences between secure attachment style and communion, birth control, and physical satisfaction, suggesting that couples with more secure attachments are able to achieve, and desire, deeper intimacy with their partner, bringing greater closeness to their relationship. Higher avoidance and anxiety are related to greater levels of dysfunction in overall functioning, desire, and satisfaction. Thus, contrary to expectations, the results surrounding the insecure attachment styles varied in the degree of communication anxiety and perceptions of sexuality. Anxious-avoidant attachment styles were positively related to sexual communication anxiety while the avoidant attachment styles appeared uncomfortable with intimate discussions and vulnerable disclosures, which may explain their greater sexual communication anxiety. Furthermore, anxious-avoidant attachment styles were negatively associated with communion while preoccupied individuals reported lower scores on permissiveness. Although not found to be significant, these results suggest that when a couple's presenting problem is sexual dysfunction, those in a helping profession could benefit from assessing a couple's attachment style and address barriers to intimacy in order to effectively treat the couple's sexual dissatisfaction.

\section{Limitations and Further Research}

Several limitations of the present study should be mentioned. The study used a crosssection of individuals rather than analyzing couples, thus the attachment style of only one partner was received. This limitation does not give insight on the potential difference in attachment styles between partners and might explain the lack of significant relationships. Further research on a more diverse sample may create a clearer picture of how attachment styles affect overall sexual satisfaction. It would be difficult to generalize results based on gender or ethnicity alone because of an underrepresentation of other ethnic groups and overrepresentation of females. The cultural demographic recruited from a southeastern college created the possible effect of conservative values overtly and covertly applied to the self-report instrument relaying information on sexual behavior, sexual satisfaction, and communication about sex. Finally, due to the need for reducing the size of the overall measurement, the present study only used four questions to assess for attachment style. Future studies should use more detailed assessment tools to fully understand respondents' attachment style and could focus on possible mediators between insecure attachment styles and sexual attitudes, in order to explain the findings between preoccupied attachment and permissive sexuality. 


\section{Conclusion}

In conclusion, the results from this study begin to provide valuable information for understanding differences between the attachment styles and positive sexuality by serving as a reminder that secure/insecure individuals have different views on sexuality. These findings also support the importance of understanding attachment styles when working with couples on sexual issues. Overall this study contributes to the body of literature by adding to the knowledge regarding sexual attitudes, communication anxiety, and sexual satisfaction within an attachment theory context.

Ainsworth, M. S., Blehar, M. C., Waters, E., \& Wall, S. (1978). Patterns of attachment: A psychological study of the strange situation. Oxford, UK: Erlbaum

Bartholomew, K., \& Horowitz, L. M., (1991). Attachment styles among young adults: A test of a four-category model. Journal of Personality and Social Psychology, 61, 226-244

Bowlby, J. (1982). Attachment and loss: Attachment (Vol. 1, 2nd ed.). New York, NY: Basic Books

Brassard, A. Dupuy, E., Bergeron, S., \& Shaver, P. R. (2015). Attachment insecurities and women's sexual function and satisfaction: The mediating role of sexual self-esteem, sexual anxiety, and sexual assertiveness. Journal of Sex Research, 52(1), 110-119

Butzer, B. \& Campbell, L. (2008). Adult attachment, sexual satisfaction, and relationship satisfaction: A study of married couples. Personal Relationships, 141-154

Davis, D., Shaver, P. R., Widaman, K. F., Vernon, M. L., Follette, W. C., \& Beitz, K. (2006) "I can't get no satisfaction": Insecure attachment, inhibited sexual communication, sexual dissatisfaction. Personal Relationships, 13, 465-483

Dempster, D., Rogers, S., Pope, A. L., Snow, M., \& Stoltz, K. B. (2015). Insecure parental attachment and permissiveness: Risk factors for unwanted sex among emerging adults. The Family Journal: Counseling and Therapy for Couples and Families, 23(4), 358-367

Hendrick, S. \& Hendrick, C. (1987). Multidimensionality of sexual attitudes. The Journal of Sex Research, 23(4), 502526

Hendrick, C., Hendrick, S. S., \& Reich, D. A. (2006). The Brief Sexual Attitudes Scale. Journal of Sex Research, 43, 76-86

Kidd, T., Hamer, M., \& Steptoe, A. (2011). Examining the association between adult attachment style and cortisol responses to acute stress. Psychoneuroendocrinology, 36, 771-779

Kimberly, C., Werner-Wilson, R., \& Motes, Z. (2013). Brief report: Expanding the Brief Sexual Attitudes Scale. Sexuality Research and Social Policy, 11, 88-93 